\title{
On the issue of the transformation of the psychological portrait of the modern Russian youth in a socio-cultural context (the case of questioning target students' groups in Don State Technical University)
}

\author{
Tamara Olenich ${ }^{1, *}$, Andrei Mekushkin ${ }^{1}$, Natalia Mamchits ${ }^{1}$, and Natia Ugrekhelidze $^{1}$ \\ ${ }^{1}$ Don State Technical University, 1, Gagarin square, 344003, Rostov-on-Don, Russia
}

\begin{abstract}
With the accordance to the formation of the psychological portrait of contemporary Russian youth in the sociocultural space, the author's hypothesis is that in the modern conditions of sociocultural communicative competence, the sociocultural space becomes a necessary aspect in the development of the socialization of the Russian students. The object of the study is the Russian student youth, and the subject is an analysis of the nature of the influence of sociocultural communicative competence on the Russian youth socialization. Such social factors as: the influence of the place of residence on the level of student competence; the influence of place of residence on the level of claims; the influence of parental capital on the level of academic performance and level of professional claims; the effect of income on competence and the effect of income on professional claims, are necessary elements for students to achieve their goal, namely to receive an elite education, based on the base they have. The results showed that the higher education of the parents and the status of the university they graduated from creates a more favorable ground for the successful career of their children. Personal experience of parents determines the ability to choose the level of professional claims of students.
\end{abstract}

\section{Introduction}

With the accordance to the psychological portrait of the contemporary Russian youth in the sociocultural space, the author's hypothesis is that under the modern conditions sociocultural communicative competence becomes a necessary aspect in the development of the socialization of the Russian students. The object of the study is the Russian student youth, and the subject is an analysis of the nature of the influence of sociocultural communicative competence on the Russian youth socialization.

The relevance of this approach is referred to the fact that within the framework of the competence-based approach, the assimilation of cultural knowledge and skills is not

\footnotetext{
* Corresponding author: tamara1970@inbox.ru
} 
sufficient. The learning process does not produce results when interacting with the student's individual semantic structures, it also does not allow students to be confident in mastering social and cultural competence.

According to the Russian researchers, the social resource allows the person to complete the course and to gain the degree. From the point of view of the profession as an indicator of the subjective reflection of student's popularity in the mass consciousness, a diploma under conditions of a developed economic, political and cultural reality of today's Russia still is a significant factor. Obviously, focusing on higher education, students proceed from the concept of the prestige of the profession they can receive.

To identify the most significant social resources that determine the learning and quality of education, such social factors are specified in the present research: place of residence; capital and income; sociocultural factor: parents' education; cultural factor: the level of communicative competence of parents; professional socialization factor: the level of communicative language competence of student; level of professional claims.

The problem of communicative competence of the Russian youth is closely linked to the professional socialization of the youth and with a number of complicated issues. One of them is a matter of linguistic and sociocultural competence of the young people. The other important issue of the professional socialization includes the factors influencing the professional socialization and the claim habits of the student youth of Russia in the sociocultural aspect.

\section{Materials and Methods}

Modern Russian sociologists study the forms of educational behavior of various segments of the society, the role of education in adapting to changing economic and social conditions, social support for the young people in the context of educational modernization, social and cultural aspects of learning foreign languages, social demand for knowledge of foreign languages etc. [22].

The process of reforming higher education in Russia, associated with the signing of the Bologna Declaration [20], actualizes the need to train a competitive specialist who must have a high level of general intelligence, communication skills as well as to be able to make independent decisions, think outside the box and adapt to changing social and economic conditions.

The origin and formation of communication, its role in social stratification was under consideration in the researches of domestic and foreign researchers (E. Aronson, E. Artsishevskaya, K. Levi-Strauss, M. Kabardova, etc.). The widespread of these concepts is logical and it is connected with a phased transition to a higher level of the education system. For example, [20], the problem of key competencies of students in the intellectual, legal, informational and other fields is highlighted. In the modern science, there is a large amount of materials describing the sociocultural content, type and dynamics of the concepts indicated.

The establishment and development of contacts between people generates the needs of joint activities, and includes exchange of information, development of a unified strategy of interaction, perception and understanding of another person and provides the opportunity to explore the essence, content and structure of communicative competence. The peculiarity of this process is formation of new type of communication: it changes the way people learn and social interacts [4]. All this is the reason to investigate the current communication competence of the modern Russian youth.

The analysis of the literature shows that communicative competence is based on skills, firstly, to correctly express and transmit information, and secondly - to listen and draw the right conclusions. Thus, communicative competence is social knowledge and skills, but the 
ability to encode and decode a variety of information transmitted and received in the process of communication can be interpreted as sociocultural competence. The goal of preparing schoolchildren for any further professional industry is formation of communicative competence, which in the context of modernization of national education, modern science and production also take on special significance [3].

Sociocultural competence is a combination of certain knowledge, skills, abilities and qualities formed in the course of the process of formal or informal language learning for intercultural communication. For most researchers, sociocultural competence has the following components: linguistic, cultural, sociolinguistic and socio-psychological [5]. The structure of most models of sociocultural communicative competence since 1995 contains much in common with the European model. It should be noted that the important components of the socio-cultural approach are:

- value attitude to the culture in general;

- respect for the world;

- the desire to be engaged in dialogue with representatives of other nations and ethnic groups;

- the use of norms of behavior, respect for the traditions and customs of culture, not only of their native language, but also of the studied one [1].

Socialization takes place within the interaction of students with a huge number of different conditions. These conditions can be interpreted as factors. «Many factors influence the success of studies in educational institutions: financial situation; health status; age; marital status; level of pre-university training; planning and control of activities (primarily educational); the adequacy of the initial ideas about the specifics of university education; form of study (full-time, evening, distance, etc.); the tuition fees; the material base of the university; qualification level of teachers and service personnel; prestige of the university» [20].

Professional socialization is a secondary socialization. It means that at different stages of its development, the same tasks of professional self-determination are solved differently [20]. Despite the fact that the family has a great influence on the professional choice of a person, the main socializing influence in terms of mastering a profession takes place not in childhood, but at much older age and beyond the family (in educational institutions, directly at the workplace, etc.) [6].

The process of professional socialization performs the function of shaping attitudes towards professional work and the ways of its implementation. The social essence of the process of professional socialization consists of the development of interest to the profession and the possibilities of its realization, as well as in the coordination of social and internal resources.

Professional socialization is a system of joint activities in which the family, children's pre-school and school institutions and the social environment as a whole take a direct part in assisting the student in choosing a profession in accordance with his or her social and individual resources. The social resource is referred to such macro-factors as: place of residence, family income, educational capital of parents, and the position of the parents. The individual resource consists of the following micro-factors: motivation, temperament, and organizational abilities of the subject of socialization $[7,8]$.

The task of the actor in the process of professional socialization is to meet the needs of the social environment, taking into account his or her social and individual factors, i.e. competent use of resources when choosing a profession. An important role in the formation of career preferences of the young people is played by objective and subjective factors: socio-economic situation, cultural capital, educational services market and labor market, state personnel policy, family expectations, choice of life and socio-professional values and goals, personal abilities, and professional self-determination. 
In the process of functioning and development of the society, the education system traditionally plays an important role as one of the factors in choosing profession. Considering the opportunities for the persons who have get a diploma, T. Ignatova obtained the following results. For boys and girls inhabiting small towns, the position with regard to the priorities that higher education offers in comparison with the young residents of the regional center is different. They want to increase their social status $(30.0 \%)$, in the second - to improve their financial situation $(28.8 \%)$, in the third - to make a career $(20.0 \%)$ [1013].

The professional choice is seriously influenced by the prestige of a particular profession. When finding a job, the youth is guided by the following factors: high wages, the prospects for professional growth and career building, a good team atmosphere. The data obtained by T. Ignatova [1] allow concluding that the studying youth of Russia, with the skillful use of their resources, has the opportunity to plan their professional career.

Since the first half of this century, the concepts of «claim» have been actively used as a term in the sociological science. Abstracting from insignificant terminological variations, it is easy to draw attention to the fact that this concept is really necessary and operationally convenient for describing and theoretical fixation of this phenomenon to specify the consumer demands of the modern man. These concepts coincide with the generally accepted definition, in which the level of claims is considered as the standard of achievement that an individual set for himself or herself and which he or she expects to achieve.

In social sciences, the range of interpretations of the concept of «claims» is quite wide and heterogeneous. In particular, E. Durkheim, G. Zimmel and P. Stompka interpret claims as «needs», P. Berger, G. Marcuse, E. Asp as «claim», R. Merton as «goal or means», M. Weber as a «requirement», E. Giddens as a «significance», P. Bourdieu as a «social expectation».

One of the factors of the social resource to determine professional aspirations of the young people are material pretensions. Having analysed the studies of the material claims of the young people of leading Russian sociologists (N. Goncharova, I. Isakova, V. Magun, V. Nichiporov, I. Shurygin, and others), we can define «claim» as the ability to use some social claims to satisfy claims to socially important requests related to material wealth.

Material claims (as a factor of social resource), regardless of family income or place of residence, dominate among the youth. The results of sociological studies prove that they are high for the half of the studying youth. Many of the young people want to occupy a higher social status than their parents, while not having the necessary factors (as components of social and internal resources) to achieve such a goal.

The youth is the object and subject of the process of succession and the system of generations. The status, income and education of parents influence the system of values and life priorities of the young people. Students from low-income families mostly rely only on themselves when they enter a higher education institution and study there. They do not rely on the personal ties of their parents and prefer to think that success can be achieved through diligence, high motivation and professional qualifications, that is, the use of their own internal resource. All these definitions are not exhaustive because of the possibility of the emergence of other concepts due to the growth and development of professional and work activity, the opportunities for students to join a certain level of social culture, and obtaining of new knowledge and skills [14-15].

To determine the impact of socio-psychological characteristics on the professionalization and claims of the Russian youth (as an element of an individual internal resource), the main groups of optants are differentiated. For example, in our opinion, it is advisable to study those students who correspond to such characteristics as: completing school (final classes), engaging in depth language learning and for those, who did not get a 
«D» or «E» mark during the last year.

In order to identify the most significant social resources that determine the processes of ensuring academic performance and quality of education, the following factors of the social resource can be identified:

1) social factor: place of residence; official capital; income;

2) sociocultural factor: parental education;

3) cultural factor: the level of communicative language competence of parents;

4) professional socialization factor: the level of communicative language competence; the level of professional claims.

For this purpose, the materials that characterizes the social status and education of parents were collected. It should be taken into account that such factors can influence the socialization processes of the children, pupils of graduating classes of schools. In accordance with the goal of the paper, the authors collected the empirical data for the study. The survey was conducted in the form of a questionnaire. The survey was hold during 2019- 2020 within 1st and 2nd year students of the specialty «Theology» of the Don State Technical University, within «Social design week» event. The number of students surveyed is 38 people. The conducted studies confirm that the place of residence, as one of the constituent social factors in the society, influences the communicative competence greatly, as evidenced by the very high correlation ratio between the respective levels: Yule-Kendall Rank Correlation Coefficient is up to 0.931 .

Such a high interest of students in getting a degree can be explained by the desire to satisfy their claims with regard to social prestige and social status. Considering the influence of other material factors, namely, the official capital of the parents, it can be stated that it is an important component of future professional claims of the student.

The data obtained by the author indicate that it is the social position of their parents is important for the students. This is due to the fact that the education received by the parents affects not only the level of the communicative competence, but also the level of students' professional claims, their choice of profession, and, consequently, their social status, income, social status and belonging to the elite of the society. Indexing parental educational capital, it must be noted that $17 \%$ of families have parents with secondary education, $40 \%$ have one parent with secondary education and one with higher education, and $43 \%$ of students have both parents with higher education [2].

The results of the study can be used in the spiritual and moral education of students of another faculty, the Faculty of Agriculture. During six years, such optional subjects as «Ethical Principles» and «Orthodox culture» has been delivered for the Faculty students who kept on obtaining successful results in mastering these disciplines.

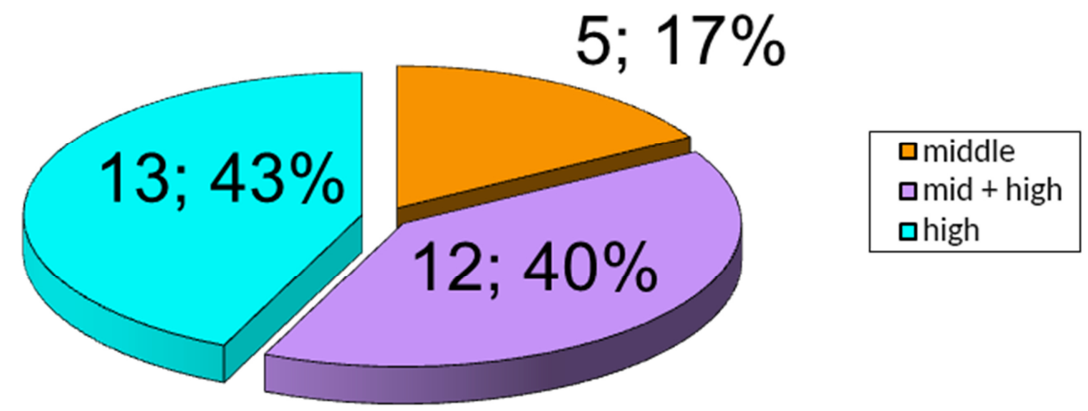

Fig. 1. Priority of the parents' capital.

Family income is part of the constituent social factor, and the position of the parents thereby significantly eliminates the claims of the young people regarding the social prestige of a higher educational institution [16-18]. 
The situation when the one needs to get proper status is created, namely, taking into account the place of work of the mother and her position and the place of work of the father and his position. Considering the following component of a social resource - family income, it must be noted that in terms of welfare, parents are distributed as follows: low welfare level $-10 \%$; average level of welfare $-17 \%$; high level of welfare $-73 \%$. The low level of welfare is also confirmed by the place of residence of the parents and his or her position [2]. A situation of «having a certain class» is created. The results obtained showed that it is the parents' higher education and the status of the university, they graduated, creates more favorable conditions for a successful career and thereby, on the personal experience of parents, makes it possible to choose the level of students' professional claims [9].

Measurements of these factors by the Yule-Kendall Rank Correlation Coefficient and by the Spearman's rank correlation coefficient, as well as empirical data showed that parents' official capital has the greatest impact on academic performance, and residence affects schoolchildren's aspirations and claims. The educational capital of parents, regardless of their place of residence, is very significant for the level of education of students [19].

For a more in-depth study of socio-psychological characteristics, the " Spiritual and moral factor in educational and professional activities» test was adapted for the 38 students who took part in the survey. The test consists of 20 questions with the help of which it is possible to determine how much a person reflects the influence of a spiritual factor (religious) on his or her professional activity and the level of professional claims. Each question has a code to determine the level of self-reflection. The data how the students divided according to their socio-psychological characteristics were obtained [21].

Table 1. The proportion of socio-psychological characteristics of students in correlation with the spiritual and moral factor (Based on the results of the survey).

\begin{tabular}{|l|c|}
\hline \multicolumn{1}{|c|}{ Peculiarities } & Proportion \\
\hline 1 Group: It makes great influence & 12 \\
\hline 2 Group It makes influence but not principal & 16 \\
\hline 3 Group Does not make influence & 10 \\
\hline
\end{tabular}

\section{Conclusions}

The study is a confirmation of the hypothesis formulated by the European researches that social indicators important for analyzing the process of professional socialization of the young people include, first of all, such components of the social resources as family capital, which includes the educational and official capital of parents, family income and place of residence [9]. But the spiritual and moral factor is also significant for the professional activities of the modern Russian youth. It is necessary to consider the location of educational institutions where young people, schoolchildren or students' study (city, village, village; large or small town). All these circumstances undoubtedly affect the quality of education received by the youth, and as a result, the trajectory of the youth's social movement, professional differentiation, characteristics of social mobility, successful implementation of professional claims, etc. Under the conditions of fierce competition among secondary school graduates (school, lyceum or gymnasium), high indices of individual resource make it possible to increase the professional and socialization potential, which is of particular importance, as it provides more advantageous positions in comparison with other social resource factors [23].

\section{References}


1. T.V. Ignatova, Materials of IV All-Russian Sociological Congress (IS RAN, Moscow, 2012)

2. N.A. Poltorak, Materials of International Conference «Transport - 2014» (Rostov State Transport University, Rostov n/D, 2014)

3. K.A. Tryma, Impact of NGOs on Higher Education Quality Assurance: European and World Experience. Actual problems of political processes and international relations in Ukraina and the countries of the world monograph (Mariupol, 2019)

4. Bologna Process Implementation Report. The European Higer Education Area in 2018, //op.europa.eu/en/publication-detail/publication/2fe152b65efe11e8ab9c01aa75ed71a1/languageen?WT.mcid=Selectedpublications\&WT.riac $=67$ 7\& WT.riaf $=706 \&$ WT.riaev $=$ search

5. A. Bubi'c, K. Ivaniševi'c, Journal of Career Development 43, 498-511 (2016)

6. R. Cheung, J. Arnold, Journal of College Student Development 55, 732-748 (2014)

7. W. Fan, F.M. Cheung, F.T.L. Leong, S.F. Cheung, Career Development 62, 194-209 (2014)

8. N.A. Fouad, S.-Y. Kim, A. Ghosh, W. Chang, C. Figueiredo, Journal of Career Assess 24, 197-212 (2016)

9. A. Frey, J. Ruppert, A. Ulrich, Psychology 09(08), 2194-2206 (2018)

10. Y. Guan, S.X. Chen, N. Levin, M.H. Bond, N. Luo, J. Xu, et al., Cross-Cultural Psychology 46, 856-872 (2015)

11. K. Hui, R.W. Lent, The Journal of Counselling Psychology 65, 98-109 (2018)

12. S.-Y. Kim, T. Ahn, N. Fouad, Journal of Career Assessment 24, 513-526 (2016)

13. X. Li, Z.J. Hou, Y. Jia, The Journal of Vocational Behavior 86, 10-19 (2015)

14. E.J. Porfeli, B. Lee, New Directions for Youth Development 134, 11-22 (2012)

15. E. Porfeli, B. Lee, International Journal for Educational and Vocational Guidance 15(2), 145-162 (2015)

16. D.R. Sawitri, P.A. Creed, Journal of Career Development 44, 530-543 (2017)

17. D.R. Sawitri, P.A. Creed, M.J. Zimmer-Gembeck, Journal of Adolescent Research 25, 551-563 (2015)

18. D.R. Sawitri, P.A. Creed, Personality and Individual Differences 81, 19-34 (2015)

19. Student Advancement of Graduates Employability with Students' Eyes. The European Students' Union, https://www.esu-online.org/wp-content/uploads/2016/07/SageEWSB-online-FINAL.pdf

20. K. Tryma, N. Salnikova, Modern Science 5, 116-126 (2019)

21. M. Tupan-Wenno, A.F. Camilleri, M. Fröhlich, Effective Approaches to Enhancing the Social Dimension of Higher Education (Knowledge Innovation Centre, Malta, 2018) http://www.ehea.info/media.ehea.info/file/Social_dimension/43/8/IDEAS-FinalReport_659438.pdf

22. J. Zalewska, Polish Sociological Review 1(205), 65-84 (2019)

23. L. Zhang, M.A. Gowan, M. Trevi-o, Journal of Managerial Psychology 29, 736-775 (2014) 